\title{
FILOSOFIA NOS TEMPOS DA PANDEMIA E O CONTRIBUTO DE KARL JASPERS
}

\author{
PHILOSOPHY IN TIMES OF PANDEMIC AND THE CONTRIBUTION OF KARL JASPERS
}

Nivaldo Duarte de Marins*

\section{RESUMO}

Uma pandemia é um problema de saúde pública. Uma pandemia envolve esforços do saber científico médico. Surge a questão: qual o contributo da filosofia nesta pandemia? Ao longo do texto, a partir da Filosofia da Existência de Karl Jaspers, expressamos uma resposta. Em primeiro lugar, valorizamos a verdade no plano científico. A verdade que é demonstrada e acatada pela comunidade científica. A verdade que advém da ciência é acolhida, por cada um de nós, através de um momento próprio de escolha e racionalidade. Esse posicionamento será chamado por Jaspers de "heroísmo solitário". No entanto, tal tipo de heroísmo é incompleto. Demonstramos no texto que o "heroísmo solitário" deve ser complementado pelo heroísmo solidário. O heroísmo solidário diz respeito à comunicação que empreendemos com a comunidade em que vivemos. A comunicação com o outro vai exercer um papel fulcral não só no nosso crescimento pessoal, mas sobretudo na disseminação da verdade científica. Por último, invocamos possíveis preconceitos contra o nosso ponto de vista, que serão rebatidos. Defendemos que o eixo complementar das duas formas de heroísmo é preservado pela presença da Razão, frente aos imensos desafios que se avizinham.

PALAVRAS-CHAVE: pandemia; Jaspers; verdade; comunicação; razão

\section{ABSTRACT}

A pandemic is a public health problem. A pandemic involves efforts of medical knowledge. The question arises: What is the contribution of philosophy in this pandemic? Through the text, based on the philosophy of the Existence of Karl Jaspers, we express an answer. First of all, we value the truth on the scientific level. The truth that is demonstrated and accepted by the scientific community. The truth that comes from science is welcomed, by each one of us, through a proper moment of choice and rationality. This position will be called by Jaspers "solitary heroism". However, such heroism is incomplete. We demonstrate in the text that the solitary heroism should be complemented by solidarity heroism. The solidarity heroism concerns communication that we carryout with the community in which we live. The communication with the other will play a central role not only in our personal growth, but above all in the dissemination of scientific truth. Finally, we invoke possible preconceptions against our point of view that will be refuted. We advogate that the complementary axis of the forms of heroism are preserved by the presence of Reason, in the face of immense upcoming challenges.

KEYWORDS: pandemic; Jaspers; truth; communication; reason

As pandemias acompanham a história da humanidade. Uma doença é considerada pandemia não só por sua extensão abarcar vários continentes, mas sobretudo pelo seu caráter infeccioso. Em termos de registros históricos, vale assinalar a Praga de Atenas ocorrida no ano

\footnotetext{
* Mestre em Psiquiatria pela Faculdade de Medicina do Porto; Mestre em Filosofia pela Faculdade de Letras do Porto; Doutorando em Filosofia pela Faculdade de Letras do Porto. E-mail: nivaldomarins@ sapo.pt.
} 
de 430 A.C., causada pela febre tifoide que vitimou mais de um quarto da população ateniense ao longo de quatro anos.

Em nosso imaginário surge, por vezes, a lembrança da chamada Gripe Espanhola que se iniciou nos Estados Unidos da América e causou aproximadamente cinquenta milhões de mortes.

A lista das pandemias é extensa e não é o nosso objetivo primeiro. No entanto, não devemos esquecer da Varíola, da Peste, HIV/AIDS ou H1N1. Como bem sabemos, nos dias que correm, um vírus que é o décimo sétimo membro da "família" Coronavírus assola o mundo. O vírus passou a ser chamado oficialmente pelo Comité Internacional de Taxonomia de vírus de: SARS-COV-2.

Uma pandemia é uma questão de saúde pública. A pergunta que surge, no nosso horizonte, é a seguinte: qual o contributo que a filosofia poderá oferecer frente à atual pandemia? É o que vamos demonstrar.

\section{A IMPORTÂNCIA DO SABER CIENTÍFICO}

A ciência coloca diante dos nossos olhos um mundo independente. A constituição básica científica não leva em conta as nossas conjecturas pessoais.

O processo da experimentação científica é uma contínua modificação de um mundo de ideias.

O método científico possui como característico o que pode ser mensurável. O mensurável é estatístico e habita a dimensão do quantitativo. A mensuração está presente na coleção de dados que agrupamos, segue no reconhecimento e designação do que vamos estudar. O pensamento científico é uma tentativa de elucidar um dado mundo de ideias. No entanto, cabe o questionamento: o que estuda a Ciência? Estuda a Natureza. A Natureza é primariamente um mundo de ideias independentes das pessoas ou de particulares tipos de sensações.

No campo científico somos levados a trabalhar com dois aspetos que acreditamos diversos, mas complementares. Delineando melhor, todo o experimento que realizamos é subjetivo, mas nenhum experimento é meramente subjetivo.

Nós teríamos dificuldades de compreender o motivo de um cientista passar trinta anos da sua vida a estudar o ciclo vital de um raro molusco duma ilha isolada do Pacífico Sul. No entanto, sabemos que para explicar o seu trabalho e ser aceito pela comunidade científica deve seguir um determinado e conhecido método de observação e mensuração. 
A ciência desvela o mundo; não custa lembrar que desvelar é deixar cair o véu. $\mathrm{O}$ desvelar leva ao desencantamento do mundo. A ciência extirpa a nossa crença na existência de seja lá o que for além do próprio saber científico.

Enfim, quais os contributos da ciência? Poderíamos enumerá-los:

a) a ciência põe em nossas mãos conhecimentos técnicos que nos permitem dominar a vida por meio da previsão;

b) a ciência contribui para a clareza;

c) a ciência contribui para o significado lógico de uma "visão de mundo".

No entanto, a validade do que descobrimos passa a ser marcada pela independência. A presença e atuação das leis da natureza, bem como os ditames da lógica permanecem independentemente de encontrarmos ou não um certo objeto científico. Os raios infravermelhos aqueciam os nossos corpos antes da sua descoberta.

Jaspers (1986, p. 369, tradução nossa) adverte-nos:

\begin{abstract}
Mas a ciência ensina-lhe (ao Homem) como trazer a infinitude sob controle, como avaliar e antecipá-la em cada possível instância. A existência de todas as coisas se desfaz em diversidades, mas a ciência aponta a unidade do que pode ser conhecido. Isso compreende uma totalidade sistemática na qual tudo é conectado com outro. Nem cogência nem unidade nem o controle da eternidade é uma aquisição imediatamente acessível aos que procuram.
\end{abstract}

Cada ciência é determinada pelo seu objetivo e pelo seu método. Cada ciência é uma visão a respeito do mundo que passa diante dos nossos olhos. A universalidade na articulação de categorias, os métodos variados, o conhecimento catalogado e exposto ao escrutínio da comunidade científica vai marcar a ciência moderna.

Todos esses elementos e características já alavancados são extremamente necessários, estamos a dizer o óbvio, mas um óbvio que precisa entrar em nossos poros, frente à pandemia que assola o mundo, deixando para trás somente "choro e ranger de dentes".

Todo o nosso conhecimento científico possui um limite. A partir desse limite, inicia-se a longa caminhada rumo ao essencial. O essencial é a existência conhecida e vivida. A existência, mesmo necessitando do saber científico, ultrapassa os limites do próprio conhecimento advindo do campo da ciência.

Avançar nessa direção implica uma determinada postura que parte do filósofo:

Porque ele (o filósofo) humildemente reconhece os limites do conhecimento possível, o filósofo permanece aberto ao desconhecido que é revelado frente a esses limites. $\mathrm{O}$ filósofo avança sem abrir mão do pensamento. Passamos a ter uma outra forma de pensar mais profunda, mais detalhada e com dificuldades de concessão maiores. Isso 
porque o pensamento passa a ser visceralmente marcado pelo nosso próprio ser e não mais filiado à deriva do encontro empírico com os objetos. (JASPERS, 2003, p.127, tradução nossa).

É uma ideia filosófica a de que todas as ciências estão relacionadas entre si. O cosmos da ciência encontra-se fundado por uma consciência filosófica. Buscamos uma unidade do saber. Essa unidade é vista como uma ideia.

Poderíamos ser levados por uma perda do nosso ímpeto face às possibilidades que a ciência nos oferece. Poderíamos lamentar-nos de que nada é sólido, de que tudo é questionável e meramente possível. É nesse momento, frente ao crescimento da dúvida, que devemos indagar: quais seriam os elementos de que o filósofo lançaria mão frente à realidade de uma pandemia?

\section{O VALOR DA VERDADE}

Não podemos negar que a própria palavra verdade já traz em si uma certa magia. No item anterior, estivemos em contacto com as dimensões, vicissitudes e horizontes da verdade científica. Um solo firme, que nos permite caminhar em direção a outros aspectos da verdade.

A verdade causa-nos dor e sofrimento, dá-nos coragem para enfrentar quer as ameaças exteriores quer aquelas que advêm da nossa percepção do que somos e do caminho que temos que percorrer. Não devemos olvidar que "o homem é uma corda estendida entre o animal e o super-humano - uma corda sobre um abismo. É perigoso transpor o abismo - é perigoso ir por este caminho - é perigoso olhar para trás - é perigoso ter uma tontura e parar de repente!" (NIETZSCHE, 2015, p. 29,). Somos levados a crer que a verdade existe em si.

Todavia, ao aproximarmo-nos e termos mais atenção do que ocorre à nossa volta, veremos que no mundo real a evidência e predomínio da verdade pode rapidamente desaparecer. A verdade que é atrelada à dependência dos acontecimentos políticos, aos discursos enganadores, ao uso da força física, ao abandono dos argumentos sensatos compromete sobretudo a evidência da nossa comprovação empírica e lógica. Passamos a ter o clamor da verdade como uma forma de logro coletivo. Um exemplo para clarificar: apregoar que um determinado medicamento surte efeito para uma grave doença apesar de uma torrente de provas científicas em contrário é abandonar a verdade.

Jaspers responde a um verdadeiro "jogo de sombras" que é realizado contra a verdade dizendo: "nós concebemos uma inequívoca verdade pousada em afirmações válidas feitas com base na experiência visual e evidência lógica" (JASPERS, 1995, p. 355, tradução nossa). 
A compreensão que alcançamos como seres racionais ocorre pela necessidade e pelo rigor dos significados das afirmações que não só proclamamos, mas os demonstramos. Como exemplo dessa imperiosa alternativa, temos as técnicas matemáticas que são o suporte da física teórica.

Pode-se, portanto, dizer mais amplamente que somente é válida aquela verdade que se torna evidente e universal. Único e real caminho a seguir no tocante à verdade científica, esta encontra em cada um de nós um momento específico: o momento da escolha. Estamos face a face, nos dias que correm, diante de um momento singular da nossa existência. Vejamos como Jaspers denomina e caracteriza este singular momento:

Existe também um verdadeiro heroísmo solitário, o qual não tem como base a comunidade e nenhum olhar para a fama. Esta autêntica independência é sustentada talvez pela harmonia interna de uma favorecida natureza e desenhada talvez inconscientemente pela histórica tradição de uma comunidade relembrada, ainda que esta consciência não encontre nada no mundo presente ao qual possa agarrar-se. (JASPERS, 2003, p. 69, tradução nossa).

Esse "verdadeiro heroísmo solitário" é um ponto de viragem da existência. O homem percebe (por meio do uso da razão e de um movimento autorreflexivo) que ele sabe muito mais a respeito de si mesmo. E parte ao encontro dessa verdade e de todas as suas repercussões. Eis o heroísmo. É um heroísmo que não brada aos sete ventos a sua força, nem faz com que o sangue que escorra de sua espada o comprove. O passo crucial que é preciso ser dado deve-se originar no meu próprio interior:

Para lá chegar, executamos aquilo a que chamamos a operação filosófica fundamental. Esta não é um método de investigação. Por intermédio desta, acontece algo em nós. Comunicá-la por palavras, através de figuras do pensamento, apenas proporciona princípios orientadores. Estes não são aplicáveis quando se pretende perceber alguma coisa, mas com eles revelam-se-nos os modos de manifestação do ser. (JASPERS, 2016, p. 44).

O homem passa a saber o que é verdadeiramente. A sua consciência de ser situa-se não apenas nos objetos do conhecimento que o cercam. Bem sabe ele que, desde os seus primeiros momentos de existência, foi um ser amparado e acalentado frente às exigências da vida. Caso não fosse, pereceria.

O homem não se encontra fadado a repetir-se; ele ultrapassa o modo em que é dado a si próprio. $\mathrm{O}$ homem encontra-se em movimento, em transformação, ele não se encontra numa situação nem num papel fixados. Porém, 
Ora justamente a maioria dos seres humanos suporta, contudo, a vida sem resmungar seriamente e crê, por conseguinte, no valor da existência, mas precisamente porque cada um se pretende e se afirma sozinho e não sai para fora de si próprio como essas excepções: para eles, tudo o que seja extra pessoal, não é de modo nenhum perceptível, ou é o quanto muito como uma tênue sombra. (NIETZSCHE, 1997, p. 54).

É por meio da sua forma de agir, num primeiro momento marcado pelo seu heroísmo solitário, que o homem virá a tomar consciência de si próprio. Esse heroísmo solitário deverá cumprir certas exigências que permitirão o vislumbre de algo maior que virá complementá-lo. Caso o homem queira fazer essa árdua caminhada em direção a si mesmo deverá abrir mão e deve deixar caído na estrada para a ação incontrolável do tempo que passa "o fato de ele se considerar mais importante que o mundo. A grande falta de fantasia, de que ele sofre, faz com que não se possa sentir na pele de outros entes, e por isso, ele partilha tão pouco quanto possível do destino e do sofrimento destes" (NIETZSCHE, 1997, p. 55).

A verdade segue caminhos que são diferentes em essência e ao mesmo tempo são fontes dos conteúdos que sustentam a vida de cada um de nós.

A partir desta última citação bem como de tudo que até agora expressamos, surgem novos questionamentos. Assim teríamos:

a) por meio de qual instrumento poderíamos nos aproximar do destino e do sofrimento daqueles que como nós perambulam por este mundo?

b) Caso tenhamos em mãos e apliquemos tal instrumento, ocorreria uma mudança no sentimento e na ação do heroísmo que já expressamos?

Buscaremos respostas.

\section{O ELO DA COMUNICAÇÃO}

Uma tragédia natural nunca atinge um único indivíduo, atinge uma comunidade. Corro o risco de ser criticado por dizer o óbvio. No entanto, se a realidade é comprovada pela resistência que nossos corpos enfrentam, a maior prova que temos desta assertiva é esbarra-nos contra uma pilha de cadáveres por ação do Coronavírus.

Para fazer frente a esta realidade que entra pelos nossos olhos e narinas, o nosso "heroísmo solitário" deve ir mais longe. O encontro com a verdade que alcançamos, via o nosso heroísmo solitário, a partir do saber científico fundamentado, só obterá o seu triunfo (em termos reais, o controle da pandemia) por meio da comunicação. No entanto, essa comunicação deve ser entrelaçada com a verdade científica. Dessa forma a comunicação passará a ter a força do conhecimento e como corolário a real e necessária ação prática. 
A forma de comunicação que ora defendemos, seguindo de perto a Jaspers, necessita cumprir duas condições que são: a percepção da dimensão histórica que cada homem possui uma faceta do heroísmo solitário. E uma segunda condição, a de "nosso ser de homens é a solidariedade humana" (JASPERS, 2017, p. 75, tradução nossa).

Isto ocorre: "como exigência de uma ilimitada comunicação. Ver e compreender os outros ajuda a ver-se claro a si mesmo, a superar a possível estreiteza de toda a historicidade encerrada em si mesma, a saltar os espaços amplos" (JASPERS, 2017, p. 43, tradução nossa).

A comunicação humana é marcada por uma diferença e um movimento próprio. A característica diferencial é observada em relação aos animais. Os animais, no seu processo de conhecimento, constroem comunidades, que são sempre idênticas, repetidas e sem a noção de historicidade.

Em relação ao importante papel da comunicação no desenvolvimento do homem, sabemos que "sua comunidade é, em primeiro lugar, nenhum estado de imediatismo, mas é imediato através de uma relação para outra coisa, para uma relação de consciência comum a propósito do mundo, para uma relação com a verdade e para com Deus" (JASPERS, 1957, p. 78, tradução nossa). A comunicação é marcada por um movimento próprio e constante. Esse movimento faz com que cada novo homem venha a inserir-se no mundo e não meramente com sua natureza biológica.

A verdade não pode estar separada da comunicação. O movimento da comunicação visa dois objetivos: a preservação e a busca da verdade. Uma conclusão torna-se imperiosa:

Todavia a verdade não pode ser separada da comunicabilidade. Ela somente aparece no tempo como uma realidade - através - da comunicação. Abstraída da comunicação, a verdade endurece em uma irrealidade. O movimento da comunicação está em um e mesmo tempo de preservação de, e a procura da verdade. Em geral, então isto (os objetos da comunicação) aplica-se ao meu ser, à minha autenticidade, e ao meu entendimento da verdade que, não é somente factual, não sendo eu, por mim mesmo um sozinho, mas eu não posso ser sozinho sem emergir do meu ser com os outros. (JASPERS, 1957, p. 80, tradução nossa).

No nosso modo de ver, é nesse momento que surge o heroísmo solidário, uma forma necessária e curial para o desenvolvimento do meu ser na relação com os outros que vivem comigo um determinado tempo histórico, suas vicissitudes e receios.

O heroísmo solidário guarda com a comunicação uma inerente vontade de aproximação para com o outro. A comunicação "necessita ser correta para encontrar a substância de todo o ser que realmente comunicasse comigo como outro o qual eu não sou, mas em solidariedade com quem eu posso sem limite da verdade vir a ser eu próprio" (JASPERS, 1957, p. 99, tradução 
nossa). A comunidade que encontramos e na qual passamos a ser inseridos nunca será encarada como a que possui a existência possível que tanto busco. Passamos a nos dar conta que os dados da realidade empírica, importantes sem dúvida, não irão preencher aquilo que almejamos. Uma tarefa a partir de um elo filosófico torna-se básico.

Em suma: a vertente do heroísmo solidário atua e transforma o meu primitivo heroísmo solitário. Para terminar esta explanação, cabe-nos buscar esclarecer como esses dois tipos de heroísmos, que se mantêm por meio da verdade e da comunicação a partir do saber científico, relacionam-se para no campo prático atuarem.

\section{DAS RELAÇÕES}

A incorporação da verdade na comunicação é um pilar do desafio que temos a nossa frente. Esta vincada relação entre a verdade e a comunicação faz com que as capacidades resolutas do homem em falar, escutar, perceber e refletir possam ser desenvolvidas.

Para alcançarmos resultados concretos frente à atual pandemia, resultados refletidos na diminuição do número de mortos, de pessoas infectadas e no decréscimo da sobrecarga dos hospitais, devemos ter em conta, no plano filosófico, como deveria ser a relação entre a verdade científica e a comunicação. Assim como a relação entre o heroísmo solitário que emana do nosso ser e o heroísmo solidário que surge das interações com os habitantes da comunidade.

Advogamos que existe em pauta uma profunda e irredutível complementaridade. É a este o aspecto que gostaríamos de chamar a devida atenção. Essa complementaridade vai abrirnos a possibilidade de conhecermos o que não sabíamos, de refletir por caminhos desconhecidos, de encontrarmos soluções inesperadas e que serão muito bem-vindas em tempos pandêmicos.

A partilha da verdade necessita encontrar "a substância de todo o ser que realmente comunicasse comigo como outro o qual eu não sou, mas em solidariedade com quem eu posso sem limite da verdade vir a ser eu próprio" (JASPERS, 1957, p. 99, tradução nossa). Acreditamos numa relação de cariz complementar que encerra o nosso ser que vive o heroísmo solitário e a comunidade em que estamos inseridos que expressa o heroísmo solidário. Partindo da concepção que ser eu próprio significa ser solitário, porém em solidão eu não sou eu mesmo. A minha existência só se torna possível quando é realizada pela comunicação com o outro. Em outros termos: numa comunidade una e segura para todos.

Discordamos que entre os dois tipos de heroísmo exista uma vinculação. Uma 
vinculação implica um traço de união que pode vir a ser alterado por fatores externos ou internos relacionados ao próprio estado vinculativo. Também discordamos que exista um abismo intransponível entre o campo dos heroísmos. Como ocorre quando Jaspers explicita os campos das ciências naturais e o campo das ciências da mente. Uma clara dicotomia é mantida. Assim sendo:

\begin{abstract}
Novamente as suas práticas de pesquisa (dos cientistas), parecem reconstruí-las como duas entidades entranhas uma para a outra. Os cientistas em ambos os domínios compartilham uma atmosfera de questionamento e pensamento. Eles entendem-se mutuamente - os cientistas naturais claramente e inequivocamente, os cientistas da mente dentro dos seus limites históricos, mas entre os dois grupos há geralmente hiatos, um abismo e muito pouco um olhar de relance para o outro lado... (JASPERS, 1986, p. 360, tradução nossa).
\end{abstract}

Da mesma forma, deixamos de lado a construção de polos — heroísmo solitário e heroísmo solidário - que guardem entre si um estado de tensão. A complementaridade que advogamos para fazer frente à pandemia que sucede entre nós deve ter em conta:

a) a complementaridade permite as características e ações próprias do outro elemento;

b) a complementaridade deve ocorrer numa perspectiva de totalidade entre os elementos envolvidos. Essa totalidade vai levar a um fortalecimento conjunto.

Por fim, a complementaridade ocorre entre todos os "pontos" existentes entre os elementos em pauta. No caso que estamos a discutir os "pontos" do heroísmo solitário e os "pontos" do heroísmo solitário devem todos ser preenchidos para que não ocorram falhas na comunicação ou distorções da verdade apregoada.

Um exemplo advindo do campo da neurociência tornará mais claro o que estamos a delinear. Na superfície neuronal existem determinados sítios que recebem o nome de receptores. Tais receptores possuem um específico “desenho". Esses receptores recebem determinadas substâncias chamadas de neurotransmissores. Para que o neurônio exerça a sua função é necessária a plena complementaridade dos sítios específicos entre os receptores e as substâncias neurotransmissoras. É esse conceito que defendemos entre o "receptor heroísmo solidário" e o "neurotransmissor heroísmo solitário" que se refletem nos dois tipos de heroísmos complementares. Caso isso venha a acontecer, a prática necessária e eficaz contra a pandemia, que ceifa um número crescente de vidas a cada dia, será eficiente.

A complementaridade necessária é movida pela Razão. Seja qual for a situação em pauta, a Razão busca complementar as realidades, na busca de laços recíprocos. No campo das ciências, frente ao crescimento crescente de novas técnicas e o desafio de inusitados domínios, a Razão clama que nada deve ser perdido. A Razão, mais do que nunca no sentido utilizado por 
Jaspers, deve ser vista como Ideia de unidade dos campos científicos.

Por outro lado, a Razão é a fonte primitiva da ordem. A Razão permanece a acompanhar, a observar os acontecimentos numa postura paciente, alerta e constante. A Razão encontra-se preparada a fazer frente aos desvarios que possam surgir. O heroísmo solitário que abre as portas à mais penetrante e pura forma do problema da clarificação do sombrio, das sôfregas bases em que nós vivemos, encontra o seu sustentacúlo na Razão que vivenciamos e por que optamos. Defendemos a concepção de que a complementaridade e por consequência o encadeamento entre os dois tipos de heroísmos, já demarcados, leva-nos a um ponto comum de origem onde o pensar isolado perde-se pelo caminho. Caso todos os argumentos que já apontamos como sendo de real valor em prol da Razão como o instrumento de complementaridade entre as duas formas de heroísmos marcados pela verdade científica e pela comunicação efetiva não forem devidamente valorizados, cabe-nos então fazermo-nos valer das palavras do mensageiro, quando ao penetrar no interior da caverna, encontra, já sem vida, os corpos de Hémon e da sua amada; "isto é uma lição para os mortais; para que vejam até que ponto o pior mal do homem é a irreflexão" (SÓFOCLES, 1970, p. 48).

\section{CONSIDERAÇÕES FINAIS}

Uma situação pandêmica como a que vivemos exige uma resposta coordenada e com um sustentáculo científico. A ciência, na famosa passagem, "nos fornece algo que o comércio de legumes não nos pode, por certo, proporcionar: métodos de pensamento, isto é, os instrumentos e uma disciplina" (WEBER, 1968, p. 45). Defendemos a concepção de que a verdade científica deve repercutir no homem por meio de um ato reflexivo como uma opção consciente, movido pela escolha interior. Estamos diante do heroísmo solitário. No entanto, como já expressamos de sobejo no texto, não basta esse heroísmo solitário marcado pelo encontro com a vertente da verdade científica. Torna-se crucial um outro aspecto.

A transformação interior do homem, com os elementos já apontados, o faz perceber que sem o contato com o outro a sua própria existência estaria tão longínqua como as estrelas do céu. A transformação interior do homem o fará inserir-se na história. Na história cotidiana que nos diz, nos momentos em que vivemos, do número de mortos pela Covid-19, do aumento do desemprego, do avançar da fome e do medo do amanhã que bate à nossa porta. Esta historicidade que tem como sustentáculos a consciência, a memória, racionalização, a aplicação da técnica faz com que cada homem deixe de lado a letargia de si mesmo e busque um 
complemento. Sem este complemento, no nosso modo de ver, não teremos condições de sair da pandemia que nos ofega.

Advogamos que uma ligação complementar deve ser feita com o heroísmo solidário, por meio do papel fulcral da comunicação. A comunicação da verdade - em sua dimensão científica frente à pandemia - faz com que o heroísmo solitário encontre o seu meio próprio. A complementaridade deve abranger todos os necessários pontos. Seria como um jogo aberto de "cartas sobre a mesa", sem meias palavras ou qualquer tipo de subterfúgio.

Não devemos abrir mão do seguinte aspecto: é só por meio do heroísmo solidário que o meu ser torna-se pleno.

A força da realidade pandêmica põe em risco a continuidade da vida comunitária. Isto faz com que o homem desenvolva a arte da conversação mantendo-se assim as vias de comunicação e expressão do seu ser.

Para finalizar, gostaríamos de chamar a devida atenção para uma característica que necessita surgir e prosperar.

Ao longo do texto defendemos que a verdade advinda do saber científico é incorporada ao heroísmo solitário por meio de um ato reflexivo e volitivo e que tal heroísmo passa a ser pleno através da comunicação com o outro dentro de uma comunidade.

Isso dá ensejo ao surgimento do heroísmo solidário que guarda uma necessária relação de complementaridade com o nosso próprio e primitivo heroísmo. O eixo dessa complementaridade será o papel e o movimento da Razão. Mesmo frente às piores tormentas ou diante das sendas mais estranhas, devemos contar com o reto caminho traçado e mantido pela Razão. É a Razão que irá nos esclarecer e fortificar os vinculos complementares que apregoamos, ela fará de tudo para manter uma unidade complementar.

Ao abandonarmos a importância fulcral da Razão como um farol a nos iluminar, estaremos bastante propensos a sermos arrastados por um conjunto de preconceitos. Tais preconceitos, como bem sabemos, tomam diversas formas e modos de atuação. Frente à situação concreta que estamos a analisar poderiamos ter que enfrentar os seguintes: 1estaríamos a criar uma imensa confusão entre um plano pessoal, por excelência, o heroísmo solitário que nasce de um momento peculiar e único e uma vertente de inegável cariz social; 2 o elo sugerido entre as duas formas de heroísmos seria abrangido por uma forma extremamente alargada de uma psicologia compreensível; 3- vozes podem se levantar e clamar que a nossa explanação é demasiadamente dedutiva, filha dileta da especulação e de uma construção com "pés de barro". Para tais objeções defenderíamos, para terminar, as seguintes linhas de 
pensamento: 1- o nosso pensamento deve situar os fatos, planificar o trabalho a ser realizado, questionar cada etapa a ser realizada, não se deixar levar pelo êxito fácil ou por dificuldades vistas como insolúveis; 2- uma visão de conjunto deve ser mantida; 3- a crítica fundamentada dos pares deve ser valorizada; 4- do ponto de vista existencial que permeia esse ensaio e frente ao imenso desafio coletivo que arrostamos, bem cabe o desígnio existencial de escolher e atuar. Ao fim e ao cabo, um imperativo ético existencial. Teríamos ao nosso lado a Razão que seria marcada pela paciência, um elemento infinito, pronta a avaliar, a defender e agir em seu tempo histórico. A nossa ação premente nos angustiantes dias que passam faz com que a complementaridade dos heroísmos, tendo como bases a verdade científica e a comunicação, seja mantida pelo esclarecimento da Razão.

\section{REFERENCIAS}

JASPERS, Karl. Basic philosophical writings. Tradução de Edith Ehrlich, Leonard H. Ehrlich e George B Pepper. New Jersey: Humanities Press, 1986.

JASPERS, Karl. Origen y meta de la história. Tradução de Fernando Vela. Barcelona: Acantilado, 2017.

JASPERS, Karl. Pequena Escola do Pensamento Filosófico. Tradução de Paulo Osório de Castro. Lisboa: Cavalo de Ferro, 2016.

JASPERS, Karl. Philosophy of existence. Tradução de Richard F. Grabay. Philadelphia: University of Pennssylvania Press, 1995.

JASPERS, Karl. Reason and existenz. Tradução de William Earle. Bremen: The Noonday Press, 1957.

JASPERS, Karl. Way to Wisdom: an introduction to philosophy. Tradução de Ralph Manheim. Yale: University Press, 2003.

NIETZSCHE, F. Assim falava Zaratustra. Tradução de Alfredo Margarido. Lisboa: Editora Babel, 2015.

NIETZSCHE, F. Humano demasiadamente humano. Tradução de Paulo Osório de Castro. Lisboa: Editora Relógio D’Água, 1997.

SÓFOCLES. Antígona. Tradução António Manuel Couto Viana .Lisboa :Editorial Verbo, 1970

WEBER, M. Ciência e política: duas vocações. Tradução de Leonidas Hegenberg e Octany Silveira da Mota. São Paulo: Editora Cultrix, 1968. 